\title{
Peningkatan Kinerja Bank Syariah: Analisis Peran Corporate Social Responsibility dan Reputasi
}

\author{
Improving sharia bank performance: Analysis of corporate social responsibility and \\ reputation
}

\section{Lailatul Mukarromah}

Program Studi D4 Keuangan Syariah, Politeknik Negeri Bandung

E-mail: lailatul.mukarromah.ksy16@polban.ac.id

\begin{abstract}
This research aims to test the influence of corporate social responsibility (CSR) on the financial performance of Sharia banks, both directly and through reputation mediation. The data used consists of primary and secondary data. Primary data was obtained from questionnaires of 215 respondents, while secondary data was obtained from the 2018 annual report of seven sharia public banks. The analysis method used in this research is partial least square (PLS) using SmartPLS software version 2.0. The findings reveal that CSR has no effect on the performance of sharia banks, and reputation cannot mediate the relationship between the two. This result contributes literature on the relationship between CSR, reputation and performance of sharia banks, and can be used as a guideline for Sharia banks to continue to carry out CSR activities.
\end{abstract}

Keywords: corporate social responsibility, performance of sharia banks, reputation, partial least square

\section{Pendahuluan}

Dalam sepuluh tahun terakhir, aset perbankan syariah global mengalami peningkatan sebagai bukti perkembangan pesat bank syariah. Pada tahun 2017 nilainya mencapai USD 1,72 triliun (Otoritas Jasa Keuangan, 2018). Perkembangan juga terjadi di bidang kelembagaan, yaitu dengan menjamurnya bank syariah di berbagai negara di dunia. Perkembangan perbankan syariah tersebut berperan penting dalam meningkatkan pembangunan dan menunjang perekonomian negara serta berkontribusi dalam stabilitas keuangan global (Kholis, 2017). Meskipun demikian, bank syariah tidak terlepas dari permasalahan. Terbatasnya skala dan volume bisnis menjadi kendala mendasar bagi perbankan syariah. Data Survei Nasional Literasi Keuangan (SNLK) 2019 OJK, juga menunjukkan bahwa indeks literasi dan inklusi bank syariah masih rendah, yaitu 8,93\% dan 9,10\%. Permasalahan lainnya adalah masih diterapkannya praktik-praktik konvensional pada bank syariah seperti yang terjadi di Malaysia. Padahal secara teori, praktik bank konvensional dan bank syariah jelas berbeda. Selain itu, di berbagai negara bank syariah masih jauh tertinggal dari bank konvensional.

Penilaian terhadap bank syariah tidak terlepas dari kinerja keuangan bank yang bersangkutan. Kinerja dapat memberikan gambaran mengenai keadaan suatu bank (Setyowati, 2019), berhasil atau tidaknya bank dalam menjalankan bisnisnya secara efektif dan efisien (Hijriyani \& Setiawan, 2017). Risiko dan peluang yang dimiliki bank dapat diketahui dengan melakukan analisis terhadap kinerja keuangan bank. Pada Gambar 1, terlihat perbandingan yang menunjukkan masih kalahnya bank syariah di Indonesia dari bank-bank syariah di negara lain dalam hal kinerja keuangan. 


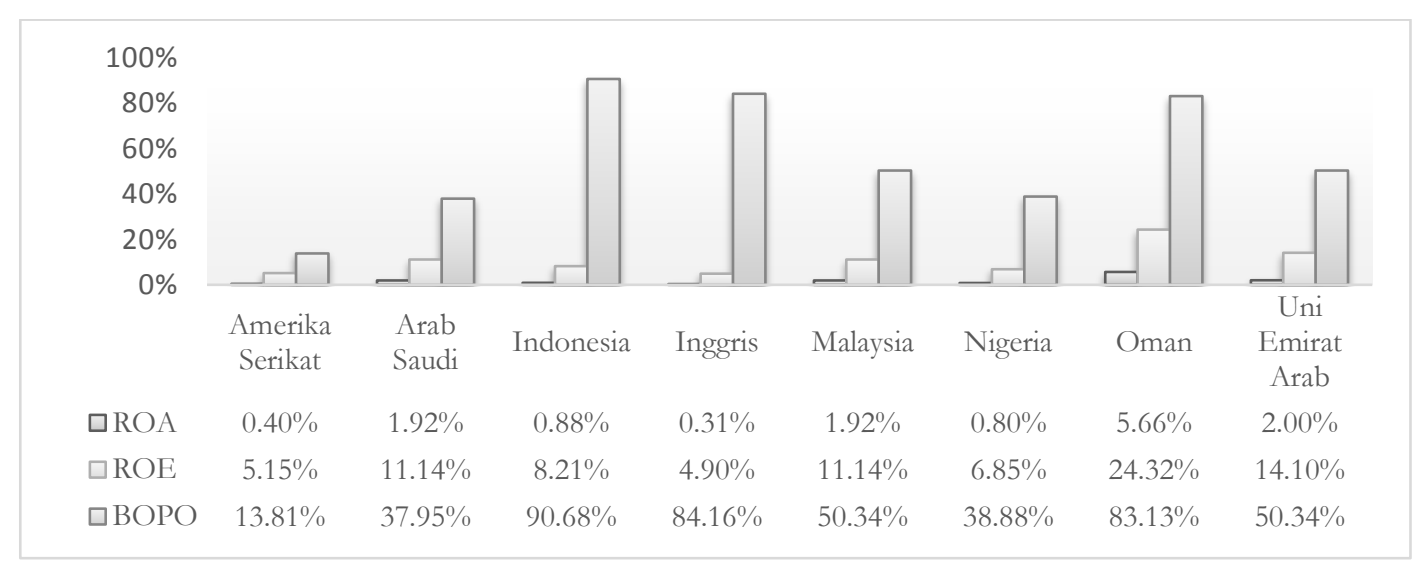

Gambar 1. Grafik Rasio Keuangan Bank Syariah Berbagai Negara

Sumber: Laporan tahunan 2018, data diolah

Menyadari pentingnya penelitian tentang kinerja bank syariah, para peneliti terdahulu telah melakukan penelitian mengenai faktor-faktor yang mempengaruhi kinerja perusahaan. Faktorfaktor tersebut antara lain faktor-faktor ekonomi makro yang tercermin pada produk domestik bruto, pertumbuhan produk domestik bruto dan tingkat inflasi (Al-Nasser Mohammed \& Muhammed, 2017), ukuran perusahaan dan keputusan investasi, serta konservatisme akuntansi dan struktur modal (Nainggolan \& Pratiwi, 2017).

BUMN di Cina harus berkonsentrasi pada kegiatan CSR dari tanggung jawab manajemen dan tanggung jawab pasar untuk meningkatkan kinerja keuangan (Rutledge et al., 2014). Kinerja keuangan bank di India ternyata dipengaruhi oleh kegiatan CSR (Maqbool \& Zameer, 2018). Tanggung jawab ekonomi, hukum, dan etika industri asuransi non-jiwa di Taiwan memiliki dampak langsung terhadap reputasi (Lee et al., 2017). Tanggung jawab ekonomi dan lingkungan memiliki efek yang penting pada sikap dan kepuasan pelanggan, sikap dan kepuasan pelanggan tersebut mempengaruhi reputasi perusahaan (E. Park, 2019). Di Ghana, UKM yang terlibat dalam kegiatan CSR memiliki reputasi yang baik (Agyemang \& Ansong, 2017). Pelanggan dapat menggunakan reputasi sebagai informasi eksternal untuk menilai kualitas suatu perusahaan. Reputasi tersebut memiliki dampak jangka panjang terhadap kinerja perusahaan (Jalilvand et al., 2017). Peningkatan reputasi secara langsung meningkatkan pangsa pasar, kemudian meningkatkan laba (Taghian et al., 2015). Oleh karena itu, penurunan reputasi perusahaan akan berkaitan dengan kerugian keuangan (Gatzert, 2015). Penelitian-penelitian di atas menunjukkan bahwa hingga saat ini pengujian CSR terhadap kinerja keuangan perbankan syariah melalui analisis persepsi nasabah belum dilakukan. Penelitian ini sangat penting untuk mengukur sejauh mana peran CSR dalam meningkatkan kinerja keuangan perbankan syariah.

Tabel. 1 Realisasi Penyaluran Dana CSR Bank Syariah

\begin{tabular}{ccr}
\hline Tahun & Nama Bank & Jumlah Dana yang Disalurkan (Rp) \\
\hline 2014 & BJBS & 1.798 .000 .000 \\
2015 & BMS & 740.100 .000 \\
2016 & BMI & 2.373 .603 .940 \\
2017 & BNIS & 11.759 .666 .263 \\
2018 & BRIS & 5.027 .540 .418 \\
2019 & BSM & 37.867 .000 .000 \\
\hline \multicolumn{3}{c}{ Sumber: Laporan tahunan, data diolah }
\end{tabular}

Pengungkapan CSR pada mulanya bersifat sukarela, namun kini statusnya meningkat menjadi wajib. Hal ini karena CSR memiliki pengaruh yang signifikan terhadap perilaku konsumen. Kinerja 
sosial dan ekonomi sebuah perbankan dapat ditentukan dari kegiatan CSR. Dalam beberapa tahun terakhir, bank syariah di Indonesia aktif terlibat dalam kegiatan CSR di berbagai bidang. Selain pengujian secara langsung mengenai hubungan CSR dan kinerja keuangan bank syariah, pengujian dilakukan melalui mediasi reputasi. Reputasi menjadi sangat penting dalam penelitian ini karena bisa menentukan keberlangsungan dari bank syariah melalui persepsi masyarakat sehingga berpengaruh terhadap kinerja keuangan bank syariah.

Perlindungan reputasi merupakan salah satu hal yang paling penting. Rasio pembiayaan macet yang meningkat dan permodalan yang cekak merupakan contoh yang menunjukkan betapa mudahnya reputasi yang baik bisa menjadi rusak. Terlebih lagi dengan latar belakang teknologi yang semakin canggih di zaman ini, berita reputasi yang buruk tersebut akan semakin mudah menyebar. Bagi bank syariah, reputasi memiliki dampak terhadap kinerja keuangan, misalnya menurunnya pendapatan yang diperoleh karena adanya perubahan yang merugikan pada para pemangku kepentingan.

Penelitian yang dilakukan untuk mengetahui hubungan antara faktor-faktor pemengaruh kinerja keuangan bank syariah sangat penting untuk menjawab permasalahan kinerja keuangan perbankan syariah saat ini. Oleh sebab itu, penelitian ini memiliki tujuan untuk mengetahui pengaruh secara langsung dan melalui mediasi reputasi mengenai hubungan antara CSR dan kinerja keuangan bank syariah. Penelitian-penelitian sebelumnya kebanyakan hanya mengukur kinerja keuangan berdasarkan bisnis utama bank syariah, namun penelitian kali ini mencoba untuk melibatkan CSR kepada kinerja bank syariah melalui persepsi nasabah.

Selama ini penelitian tentang hubungan CSR, reputasi, dan kinerja keuangan hanya dilakukan pada perusahaan-perusahaan umum. Belum ada penelitian yang secara khusus menghubungkan CSR, reputasi, dan kinerja keuangan bank syariah. Bagi perbankan syariah, kehadiran penelitian yang menghubungkan ketiga variabel ini dipandang penting karena kinerja keuangan perbankan syariah selama ini hanya mengandalkan sektor bisnis. Padahal, para pakar CSR meyakini bahwa CSR dan reputasi juga mampu berperan meningkatkan kinerja korporasi. Mengingat pada saat ini kinerja perbankan syariah kurang kompetitif terhadap bank konvensional, maka peran CSR dan reputasi sangat diperlukan. Untuk itulah, maka penelitian ini mengestimasi hubungan CSR, reputasi, serta kinerja keuangan bank syariah di wilayah Indonesia, khususnya Bandung Raya. Alasan pemilihan Indonesia sebagai objek penelitian adalah karena jumlah industri perbankan syariah dan penduduk Muslim banyak di wilayah ini, serta Indonesia memegang posisi tertinggi untuk negara dengan lembaga pendidikan keuangan syariah terbanyak juga negara yang menghasilkan research papers keuangan syariah terbanyak (Otoritas Jasa Keuangan, 2018).

Penelitian ini dilakukan berdasarkan rekomendasi dari beberapa peneliti terdahulu. Studi masa depan harus menganalisis hubungan antara CSR dan kinerja di industri keuangan (Lee et al., 2017). Perlu adanya eksplorasi untuk mengetahui dampak dari variabel seperti kegiatan CSR yang dapat diterapkan di seluruh layanan profesional (Jalilvand et al., 2017). Kemudian penyelidikan terhadap efek moderasi reputasi perusahaan pada hubungan antara kinerja perusahaan dan mitra sosial dapat dilakukan dengan pengumpulan data primer (Liu et al., 2019).

\section{Kajian Pustaka}

\subsection{Corporate Social Responsibility dan Kinerja Bank Syariah}

Faktor yang berpengaruh terhadap peningkatan kinerja organisasi salah satunya adalah CSR. Pelaksanaan CSR di lembaga keuangan syariah adalah unik karena didasarkan pada hukum syariah (Menne, 2016). CSR berhubungan positif dengan kinerja perusahaan (Saeidi et al., 2015). CSR memiliki efek positif pada kinerja keuangan perusahaan di Korea. Efek CSR terhadap kinerja keuangan perusahaan berbeda-beda, tergantung pada karakteristik industri. Perusahaan harus meningkatkan kinerja keuangan dengan memberlakukan CSR sebagai faktor yang berkelanjutan di 
sebuah perusahaan (Oh \& Park, 2015). CSR memiliki hubungan positif yang signifikan dengan kinerja keuangan UKM di Ghana. Kegiatan CSR oleh UKM di Ghana tersebut menyebabkan peningkatan kinerja keuangan (Agyemang \& Ansong, 2017). Di Cina, BUMN harus berkonsentrasi pada kegiatan CSR dari tanggung jawab manajemen dan tanggung jawab pasar untuk meningkatkan kinerja keuangan (Rutledge et al., 2014). Pengintegrasian CSR ke dalam operasi bisnis menyebabkan target keuangan menjadi lebih mudah tercapai dan kinerja keuangan bank di India menjadi lebih baik (Maqbool \& Zameer, 2018). Sebagai hasil dari pembahasan di atas, hipotesis berikut diusulkan:

H1: CSR berpengaruh positif terhadap kinerja bank syariah

\subsection{Peran Mediasi Reputasi}

Reputasi perusahaan merupakan aset tidak berwujud bagi suatu perusahaan. Sebuah aspek kunci dari reputasi perusahaan adalah persepsi para pemangku kepentingan terhadap tanggung jawab sosial perusahaan, atau secara spesifik adalah persepsi mereka tentang seberapa baik inisiatif atas tanggung jawab sosial perusahaan dan hasilnya dalam memenuhi nilai-nilai dan harapan sosial dan lingkungan para pemangku kepentingan (Jalilvand et al., 2017). Peningkatan reputasi industri asuransi non-jiwa dapat disebabkan oleh pemenuhan kegiatan CSR. Aspek tanggung jawab sosial secara signifikan dan positif mempengaruhi reputasi perusahaan (Lee et al., 2017). Survei oleh World Economic Forum menunjukkan sekitar 60\% responden mengaku bahwa reputasi perusahaan mewakili lebih dari $40 \%$ dari nilai perusahaan tersebut, dan $77 \%$ responden merasa bahwa peningkatan reputasi itu penting. Reputasi perusahaan secara konsisten dapat mengerahkan dampak positif pada ROA, ROE dan EPS (Weng \& Chen, 2017).

Perusahaan yang mengembangkan reputasi yang baik akan menciptakan keunggulan kompetitif bagi perusahaan tersebut, terutama ketika perusahaan itu bersaing untuk mendapatkan pelanggan yang ingin mengalami produk atau layanan untuk pertama kalinya (Jalilvand et al., 2017). Dampak reputasi perusahaan pada perilaku pemangku kepentingan sangat relevan untuk memahami dampak utama dari reputasi perusahaan pada kinerja keuangan perusahaan. Perubahan negatif yang sebenarnya dalam perilaku pemangku kepentingan dapat menyebabkan efek negatif pada arus kas yang pada gilirannya akan berdampak negatif pada kinerja keuangan (Gatzert, 2015). Hubungan antara CSR dan kinerja perusahaan adalah hubungan yang sepenuhnya dimediasi. Salah satu mediator dalam hubungan tersebut adalah reputasi (Saeidi et al., 2015). Kinerja keuangan jangka panjang dipengaruhi secara langsung oleh CSR dan juga secara tidak langsung melalui reputasi (S. H. Park, 2017). Penelitian di Ghana menunjukkan bahwa UKM dengan CSR yang baik diposisikan untuk mencapai reputasi yang baik, yang akhirnya menyebabkan peningkatan kinerja keuangan (Agyemang \& Ansong, 2017). Sebagai hasil dari pembahasan di atas, hipotesis berikut diusulkan:

H2: Reputasi dapat memediasi hubungan antara CSR dan kinerja bank syariah

\subsection{Hipotesis Model}

Berdasarkan argumen penelitian dan dua hipotesis yang dirumuskan, model hipotesis berikut dikembangkan. Model ini menggambarkan hubungan langsung antara CSR dan kinerja bank syariah tanpa variabel mediasi. Selain itu, model ini menggambarkan bahwa CSR mempengaruhi kinerja bank syariah melalui variabel mediasi reputasi. Bank syariah yang berkomitmen terhadap kegiatan CSR cenderung dapat meningkatkan reputasi, yang kemudian akan diterjemahkan ke dalam peningkatan kinerja keuangan. 


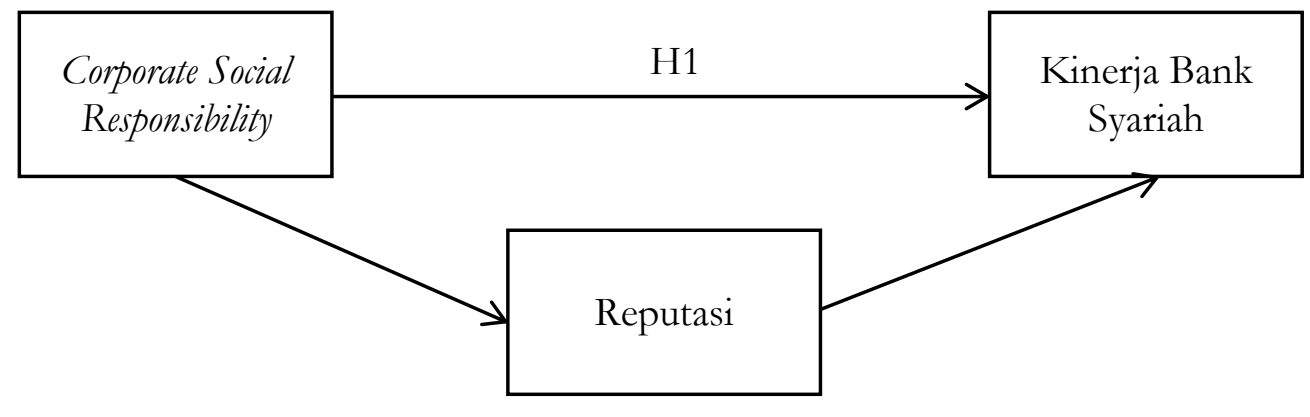

$\mathrm{H} 2$

Gambar 2. Kerangka Konseptual

\section{Metode Penelitian}

\subsection{Sampel dan Pengumpulan Data}

Data untuk penelitian ini terakumulasi melalui purposive sampling, yakni memilih nasabah yang mengerti CSR di perbankan syariah di wilayah Bandung Raya. Adapun pilihan terhadap populasi Bandung Raya adalah karena (1) menurut Badan Pusat Statistik Provinsi Jawa Barat, perbankan syariah di wilayah Bandung Raya merupakan salah satu wilayah perbankan syariah yang paling banyak jaringan perkantorannya, (2) perbankan syariah di wilayah ini memiliki jumlah aset dan dana pihak ketiga yang tergolong tinggi di Indonesia (Otoritas Jasa Keuangan, 2019), dan (3) praktik CSR banyak dilakukan di wilayah ini (Rudito, 2014; Nirmalasari \& Ulum, 2014).

Penelitian ini berjenis kuantitatif. Data primer dan sekunder digunakan sekaligus dalam penelitian ini. Jenis data primer digunakan pada variabel CSR dan reputasi, yaitu berupa kuesioner. Sementara itu, jenis data sekunder digunakan pada variabel kinerja bank syariah, yaitu berupa laporan tahunan bank umum syariah tertentu pada tahun 2018. Data sekunder yang digunakan dalam penelitian ini diperoleh dari website resmi masing-masing bank syariah. Penggunaan data primer dan sekunder pada penelitian ini dimaksudkan untuk mempertinggi tingkat validitas hasil penelitian. Data sekunder tersebut digunakan untuk mendukung data primer.

Nasabah diminta untuk menjawab beberapa item kuesioner berdasarkan persepsi pribadi. Dari penyebaran link kuesioner, didapat 227 tanggapan dan 61 diantaranya tidak valid. Selain itu, sebanyak 58 kuesioner didistribusikan dan 9 diantaranya tidak kembali, sehingga terdapat 215 kuesioner yang layak digunakan untuk input data. Mengenai demografi, mayoritas responden adalah perempuan (54,42\%), berusia 20-29 tahun (79,53\%), berpendidikan D4/S1 (50,23\%), berstatus pelajar/mahasiswa $(57,21 \%)$ dan nasabah dari Bank Negara Indonesia Syariah (30,70\%).

Kuesioner survei terdiri dari dua bagian. Bagian pertama memuat informasi demografi responden, sedangkan bagian kedua mencatat persepsi masing-masing responden terhadap masingmasaing variabel dalam model. Informasi demografi yang ditanyakan adalah jenis kelamin, usia, tingkat pendidikan, dan pekerjaan. Bagian kedua terdiri dari dua item, item pertama memuat pernyataan tentang CSR yang diadaptasi dari Su et al. (2017) dan Jalilvand et al. (2017), dan item kedua terdiri dari pernyataan tentang reputasi yang diadaptasi dari Su et al. (2014), Jalilvand et al. (2017) dan Taghian et al. (2015). Skala likert lima poin digunakan untuk memfasilitasi pengukuran. Para responden diminta untuk mengisi kuesioner dan menunjukkan kondisi mereka saat ini untuk setiap item variabel.

\subsection{Variabel Penelitian}

Variabel independen, variabel dependen dan variabel mediator merupakan variabel-variabel yang digunakan dalam penelitian ini. CSR sebagai variabel independen diukur berdasarkan persepsi nasabah dengan menggunakan kuesioner. 
Selain itu, penelitian ini menggunakan variabel dependen berupa kinerja bank syariah. Variabel dependen dalam penelitian ini diproksikan dengan indikator-indikator seperti pada Tabel 2. Indikator rentabilitas lebih banyak digunakan karena laba mampu mencerminkan kemampuan perusahaan dalam melakukan produktivitas terhadap aset yang dimiliki (Setiawan \& Sari, 2018).

Tabel. 2 Indikator Variabel Dependen

\begin{tabular}{lll}
\hline Parameter & & \multicolumn{1}{c}{ Indikator } \\
\hline Profil risiko (risk profile) & a. & Non Performing Financing (NPF) \\
& b. & Financing to Deposit Ratio (FDR) \\
\hline Rentabilitas (earnings) & c. & Return On Asset (ROA) \\
& d. & Net Operating Margin (NOM) \\
& e. & Beban Operasional Pendapatan Operasional (BOPO) \\
\hline Permodalan (capital) & f. & Capital Adequacy Ratio (CAR) \\
\hline
\end{tabular}

Penelitian ini juga menggunakan variabel mediator untuk mengevaluasi apakah reputasi bank syariah memperkuat atau justru memperlemah hubungan antara CSR dan kinerja keuangan bank syariah.

\subsection{Teknik dan Metode}

Structural Equation Model (SEM) dengan alternatif teknik Partial Least Square (PLS) berbasis variance digunakan agar tujuan dalam penelitian tercapai. Penggunaan PLS dalam penelitian ini adalah karena asumsi yang dibutuhkan dalam PLS tidaklah banyak, dapat diterapkan pada seluruh skala data dan sampel yang digunakan tidak harus besar. Oleh karena itu, SmartPLS versi 2.0 digunakan untuk menghitung model penelitian yang diusulkan. Sementara itu, pengujian pengaruh mediasi variabel reputasi terhadap hubungan antara CSR dan kinerja bank syariah, dilakukan dengan menggunakan sobel test dengan rumus sebagai berikut.

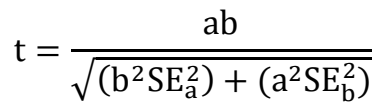

Keterangan:

$\mathrm{a}=$ koefisien regresi variabel CSR terhadap variabel reputasi.

$\mathrm{b}=$ koefisien regresi variabel reputasi terhadap variabel kinerja bank syariah.

$\mathrm{SE}_{\mathrm{a}}=$ standard error of estimation dari pengaruh variabel CSR terhadap variabel reputasi.

$\mathrm{SE}_{\mathrm{b}}=$ standard error of estimation dari pengaruh variabel reputasi terhadap variabel kinerja bank syariah.

\section{Hasil dan Pembahasan}

\subsection{Reability dan Validity pada Measurement Model}

Tabel 3 menunjukkan bahwa data yang digunakan dalam model sudah baik. Hal tersebut dibuktikan dengan nilai loading factor untuk masing-masing indikator berada pada rentang 0,68 hingga 0,94. Nilai composite reliability dari variabel berkisar mulai 0,86 hingga 0,91, sementara Cronbachs Alpha memiliki rentang dari 0,80 hingga 0,88, semuanya di atas 0,7 (ambang batas yang direkomendasikan oleh Chin \& Dibbern (2010) dan Vinzi et al. (2010)).

Convergent validity dalam penelitian ini adalah puas karena nilai AVE berkisar antara 0,56 hingga 0,83 sebagaimana disajikan dalam Tabel 3. Indeks ini menunjukkan convergent validity variabel yang baik.

Discriminant validity sudah memadai, ditunjukkan dengan akar kuadrat AVE lebih tinggi nilainya daripada korelasi antarkonstruk sebagaimana disajikan dalam Tabel 4. 
Tabel. 3 Hasil dari Measurement Model

\begin{tabular}{|c|c|c|c|c|c|c|c|c|}
\hline Konstruk & Indikator & Mean & $\begin{array}{l}\text { Standard } \\
\text { Deviation }\end{array}$ & $\begin{array}{l}\text { Loading } \\
\text { Factor }\end{array}$ & $\begin{array}{c}\mathrm{T}- \\
\text { Statistics }\end{array}$ & $\begin{array}{l}\text { Composite } \\
\text { Reliability }\end{array}$ & AVE & $\begin{array}{c}\text { Cronbachs } \\
\text { Alpha }\end{array}$ \\
\hline \multirow[t]{8}{*}{ CSR } & $\begin{array}{l}\text { Bank syariah } \\
\text { bertanggung jawab } \\
\text { terhadap lingkungan. }\end{array}$ & 3,82 & 0,06 & 0,77 & 12,39 & 0,86 & 0,56 & 0,80 \\
\hline & $\begin{array}{lr}\text { Bank } & \text { syariah } \\
\text { memberikan } & \text { timbal } \\
\text { balik } & \text { kepada }\end{array}$ & 3,87 & 0,06 & 0,72 & 12,17 & & & \\
\hline & masyarakat setempat. & & & & & & & \\
\hline & $\begin{array}{l}\text { Bank syariah } \\
\text { memperlakukan para } \\
\text { pemangku } \\
\text { kepentingan dengan } \\
\text { baik. }\end{array}$ & 4,00 & 0,06 & 0,72 & 11,17 & & & \\
\hline & $\begin{array}{l}\text { Bank syariah } \\
\text { membantu } \\
\text { menyelesaikan } \\
\text { masalah sosial. }\end{array}$ & 3,93 & 0,05 & 0,76 & 16,86 & & & \\
\hline & $\begin{array}{l}\text { Bank syariah } \\
\text { mengalokasikan }\end{array}$ & 3,85 & 0,06 & 0,76 & 12,15 & & & \\
\hline & $\begin{array}{lr}\text { sebagian } & \text { sumber } \\
\text { dayanya } & \text { untuk }\end{array}$ & & & & & & & \\
\hline & kegiatan filantropi. & & & & & & & \\
\hline \multirow[t]{7}{*}{$\mathrm{R}$} & $\begin{array}{l}\text { Bank syariah sangat } \\
\text { dihormati. }\end{array}$ & 4,00 & 0,06 & 0,72 & 11,68 & 0,90 & 0,58 & 0,88 \\
\hline & Bank syariah sukses. & 3,81 & 0,04 & 0,80 & 20,18 & & & \\
\hline & Bank syariah mapan. & 3,78 & 0,04 & 0,84 & 23,07 & & & \\
\hline & Bank syariah stabil. & 3,90 & 0,04 & 0,80 & 19,77 & & & \\
\hline & $\begin{array}{l}\text { Bank syariah menjual } \\
\text { produk-produk } \\
\text { berkualitas tinggi. }\end{array}$ & 3,84 & 0,08 & 0,73 & 9,46 & & & \\
\hline & $\begin{array}{l}\text { Bank syariah adalah } \\
\text { lembaga keuagan } \\
\text { yang inovatif. }\end{array}$ & 3,97 & 0,06 & 0,73 & 12,48 & & & \\
\hline & $\begin{array}{lr}\text { Bank } & \text { syariah } \\
\text { memiliki } & \text { sesuatu } \\
\text { yang unik } & \text { untuk } \\
\text { ditawarkan. } & \\
\end{array}$ & 4,00 & 0,07 & 0,68 & 9,68 & & & \\
\hline \multirow[t]{3}{*}{ K } & Non Performing & 0,04 & 0,12 & 0,94 & 8,01 & 0,91 & 0,83 & 0,81 \\
\hline & Financing (NPF) & & & & & & & \\
\hline & $\begin{array}{l}\text { Capital Adequacy Ratio } \\
\text { (CAR) }\end{array}$ & 0,21 & 0,19 & 0,88 & 4,75 & & & \\
\hline
\end{tabular}

Sumber: Hasil pengolahan data dengan SmartPLS 2.0 
Tabel. 4 Koefisien Korelasi dan Akar AVE

\begin{tabular}{lccc}
\hline & CSR & R & K \\
\hline CSR & $\mathbf{0 , 7 5}$ & & \\
$\mathrm{R}$ & 0,72 & $\mathbf{0 , 7 6}$ & \\
$\mathrm{K}$ & 0,10 & 0,03 & $\mathbf{0 , 9 1}$ \\
\hline
\end{tabular}

Sumber: Hasil pengolahan data dengan SmartPLS 2.0

\subsection{Structural Model}

Hasil R-square menjelaskan 52,26\% dan 1,47\% dari varians dari reputasi dan kinerja bank syariah. Varians dari variabel endogen lebih kecil dari 0,25 , menunjukkan bahwa efek eksogen variabel pada variabel endogen sebagian besar tidak ditangkap oleh model. Singkatnya, model memiliki penjelasan yang lemah.

Tabel. 5 Path Estimates dan Pengujian Hipotesis

\begin{tabular}{cccccl}
\hline Hipotesis & $\begin{array}{c}\text { Hubungan } \\
\text { Antarvaribel }\end{array}$ & $\begin{array}{c}\text { Standard Path } \\
\text { Loadings }\end{array}$ & T-Values & $\begin{array}{c}\text { Standard } \\
\text { Error }\end{array}$ & Hasil Uji Hipotesis \\
\hline H1 & $\mathrm{C}->\mathrm{K}$ & 0,17 & 1,12 & 0,15 & Tidak didukung \\
H2 & $\mathrm{C}->\mathrm{R}$ & 0,72 & 14,38 & 0,05 & Didukung \\
& $\mathrm{R}->\mathrm{K}$ & $-0,09$ & 0,62 & 0,15 & Tidak didukung \\
\hline
\end{tabular}

Setelah skala pengukuran divalidasi, model struktural dianalisis untuk menguji usulan model konseptual. Hasilnya dilaporkan dalam Tabel 5. CSR tidak mempengaruhi kinerja bank syariah secara signifikan $(\beta=0,17)$. Oleh karena itu, H1 tidak didukung. Reputasi juga tidak mempengaruihi kinerja bank syariah $(\beta=-0,09)$. Untuk menguji efek mediasi reputasi pada hubungan CSR dan kinerja bank syariah, dilakukan pengujian dengan menggunakan sobel test. Hasil t hitung sobel test adalah sebagai berikut.

$$
\begin{aligned}
t & =\frac{0,7229 \times(-0,0930)}{\sqrt{\left((-0,0930)^{2} \times 0,0503^{2}\right)+\left(0,7229^{2} \times 0,1514^{2}\right)}} \\
& =\frac{-0,0672}{0,1095} \\
& =-0,6139
\end{aligned}
$$

Berdasarkan hasil perhitungan di atas, dapat dilihat bahwa pengaruh CSR terhadap kinerja bank syariah dimediasi oleh reputasi sebesar -0,61. Nilai koefisien t hitung ini lebih kecil dari 1,96 ( $<\mathrm{t}$ tabel). Dapat disimpulkan bahwa tidak terjadi pengaruh mediasi secara signifikan. Dengan demikian, reputasi tidak dapat memediasi hubungan antara CSR dan kinerja bank syariah atau dengan kata lain $\mathrm{H} 2$ juga tidak didukung.

\section{Penutup}

Penelitian ini mengeksplorasi hubungan antara CSR, reputasi dan kinerja bank syariah, melalui pendekatan mediasi. Hasilnya menunjukkan bahwa CSR tidak berpengaruh secara signifikan terhadap kinerja bank syariah dan reputasi tidak dapat memediasi hubungan di antara keduanya. Adanya reputasi sebagai variabel mediasi justru memperlemah hubungan antara CSR dan kinerja bank syariah. Hasil lebih lanjut menunjukkan bahwa bank syariah memiliki reputasi yang baik ketika mereka melakukan kegiatan CSR, tapi tidak ditemukan bukti yang cukup bahwa kegiatan CSR tersebut meningkatkan kinerja keuangan. Ini berarti bahwa peningkatan kinerja bank syariah disebabkan oleh faktor lain selain CSR.

Namun, bank syariah tidak dapat menjadikan hasil penelitian sebagai acuan bagi bank untuk mengurangi kegiatan CSR. Bank syariah tetap memiliki kewajiban untuk melaksanakan kegiatan 
CSR. Kegiatan CSR yang dilakukan bank syariah tampaknya tidak memaksimalkan keuntungan, tetapi merupakan pemenuhan fungsi manfaat sosial bank syariah untuk melayani kepentingan publik dan untuk mempromosikan bank syariah itu sendiri.

Penelitian ini menganalisis pengaruh CSR terhadap kinerja bank syariah yang diukur dengan beberapa indikator. Hasil penelitian ini mendukung penelitian sebelumnya yang menemukan bahwa CSR memiliki dampak negatif terhadap kinerja keuangan (Sekhon \& Kathuria, 2019; Kim \& Oh, 2019; Madorran \& Garcia, 2016; Elouidani \& Zoubir, 2015). Tidak ada hubungan yang signifikan antara pengungkapan CSR dan kinerja keuangan (Thao \& Le, 2019; Ho et al., 2019). Hubungan antara CSR dan kinerja keuangan salah satunya adalah negatif (Mikołajek-Gocejna, 2016). Tidak ada bukti yang cukup jelas yang menyatakan bahwa perusahaan dengan reputasi tinggi menunjukkan kinerja yang lebih baik daripada perusahaan nonreputasi (Tomak, 2014). Reputasi perusahaan ternyata tidak berpengaruh signifikan terhadap kinerja (Afum et al., 2020). Penelitian ini memberikan kontribusi pada literatur mengenai CSR dan kinerja keuangan bank syariah, bahwa terdapat ketidakkonsistenan pada hubungan antara CSR dan kinerja keuangan. Terdapat hubungan yang positif dan signifikan antara pengeluaran CSR dan kinerja keuangan perusahaan (Salehi et al., 2018). Ada kesinambungan antara reputasi yang baik dan peningkatan kinerja (Kaur \& Singh, 2020). Secara khusus, penelitian ini memberikan kontribusi pada literatur CSR dan hubungan antara CSR dan kinerja keuangan bank syariah melalui persepsi nasabah Bandung Raya dan rasio keuangan.

Hasil penelitian ini dapat dijadikan pedoman oleh pengambil keputusan pada bank syariah bahwa peningkatan kinerja bank syariah tidak akan terjadi dengan cara meningkatkan kegiatan CSR. Adapun usaha CSR bank syariah mengarah pada peningkatan reputasi. Sangat penting bagi bank syariah untuk tidak hanya memperhatikan hubungan dengan pemangku kepentingan mereka, tetapi juga penting untuk melindungi martabat dalam interaksi sosial. Meskipun CSR tidak berpengaruh terhadap peningkatan kinerja bank syariah, kegiatan CSR tetap harus dilakukan. Bank syariah harus menyadari bahwa kegiatan CSR yang dilakukan bukan semata-mata untuk mencari keuntungan, tetapi merupakan wujud tanggung jawab sosial untuk mengurangi permasalahan sosial dan lingkungan. Selain itu, dengan adanya kegiatan CSR, bank syariah dapat dipromosikan. Dengan demikian, bank syariah dapat memperoleh manfaat dari upaya pelaksanaan kegiatan CSR.

Penelitian hanya difokuskan pada hubungan antara CSR, reputasi dan kinerja bank syariah di wilayah Bandung Raya. Oleh karena itu, penelitian lebih lanjut dengan fokus pada industri yang sama atau industri jasa lainnya perlu dilakukan dengan penambahan objek penelitian. Mengingat masih terdapatnya ketidakkonsistenan pada hubungan antara CSR dan kinerja keuangan, maka dianjurkan pula bahwa penelitian masa depan menambah variabel yang memediasi hubungan diantara keduanya, seperti ukuran perusahaan, keuntungan kompetitif, kepuasan dan loyalitas pelanggan.

\section{Daftar Pustaka}

Afum, E., Agyabeng-Mensah, Y., Sun, Z., Frimpong, B., Kusi, L. Y., \& Acquah, I. S. K. (2020). Exploring the link between green manufacturing, operational competitiveness, firm reputation and sustainable performance dimensions: a mediated approach. Journal of Manufacturing Technology Management. https://doi.org/10.1108/JMTM-02-2020-0036

Agyemang, O. S., \& Ansong, A. (2017). Corporate social responsibility and firm performance of Ghanaian SMEs. Journal of Global Responsibility. https:/ / doi.org/10.1108/jgr-03-2016-0007

Al-Nasser Mohammed, S. A. S., \& Muhammed, D. J. (2017). Financial crisis, legal origin, economic status and multi-bank performance indicators Evidence from Islamic banks in developing countries. Journal of Applied Accounting Research. https://doi.org/10.1108/JAAR-07-2014-0065 
Chin, W. W., \& Dibbern, J. (2010). An Introduction to a Permutation Based Procedure for MultiGroup PLS Analysis: Results of Tests of Differences on Simulated Data and a Cross Cultural Analysis of the Sourcing of Information System Services Between Germany and the USA. In Handbook of Partial Least Squares. https://doi.org/10.1007/978-3-540-32827-8_8

Elouidani, A., \& Zoubir, F. (2015). Corporate social responsibility and financial performance. African J. of Accounting, Auditing and Finance. https://doi.org/10.1504/ajaaf.2015.071749

Gatzert, N. (2015). The impact of corporate reputation and reputation damaging events on financial performance: Empirical evidence from the literature. European Management Journal. https://doi.org/10.1016/j.emj.2015.10.001

Hijriyani, N. Z., \& Setiawan, S. (2017). Analisis Profitabilitas Perbankan Syariah di Indonesia sebagai Dampak Dari Efisiensi Operasional. Jurnal Kajian Akuntansi. https://doi.org/10.33603/jka.v1i2.823

Ho, A. Y.-F., Liang, H.-Y., \& Tumurbaatar, T. (2019). The Impact of Corporate Social Responsibility on Financial Performance: Evidence from Commercial Banks in Mongolia. https://doi.org/10.1108/s2514-465020190000007006

Jalilvand, M. R., Nasrolahi Vosta, L., Kazemi Mahyari, H., \& Khazaei Pool, J. (2017). Social responsibility influence on customer trust in hotels: mediating effects of reputation and wordof-mouth. Tourism Review. https://doi.org/10.1108/TR-09-2016-0037

Kaur, A., \& Singh, B. (2020). Disentangling the reputation - performance paradox: Indian evidence. Journal of Indian Business Research. https://doi.org/10.1108/JIBR-02-2018-0081

Kholis, N. (2017). Potret Perkembangan Dan Praktik Keuangan Islam Di Dunia. Millah: Jurnal Studi Agama, Universitas Indonesia. https://doi.org/10.20885/millah.vol17.iss1.art1

Kim, W. S., \& Oh, S. (2019). Corporate social responsibility, business groups and financial performance: a study of listed Indian firms. Economic Research-Ekonomska Istrarivanja . https://doi.org/10.1080/1331677X.2019.1637764

Lee, C.-Y., Chang, W.-C., \& Lee, H.-C. (2017). corporate reputation and customer loyalty-Evidence from the Taiwan Non-life insurance industry. Social Responsibility Joural, 13(2), An investigation of the effects of corporate socia. https://doi.org/10.1108/SRJ-01-2016-0006

Liu, X., Vredenburg, H., \& Daellenbach, U. (2019). The moderating effect of corporate reputation on inter-firm alliance impact on company performance. European Business Review. https://doi.org/10.1108/EBR-12-2017-0232

Madorran, C., \& Garcia, T. (2016). Corporate social responsibility and financial performance: The Spanish case. RAE Revista de Administracao de Empresas. https://doi.org/10.1590/S0034759020160103

Maqbool, S., \& Zameer, M. N. (2018). Corporate social responsibility and financial performance: An empirical analysis of Indian banks. Future Business Journal. https://doi.org/10.1016/j.fbj.2017.12.002

Menne, F. (2016). Evidence of CSR Practices of Islamic Financial Institutions in Indonesia. In Advances in Islamic Finance, Marketing, and Management. https://doi.org/10.1108/978-1-78635899-820161018

Mikołajek-Gocejna, M. (2016). The Relationship between Corporate Social Responsibility and Corporate Financial Performance - Evidence from Empirical Studies. In Comparative Economic Research. https://doi.org/10.1515/cer-2016-0030 
Nainggolan, I. P. M., \& Pratiwi, M. W. (2017). Analisis Faktor-Faktor Yang Mempengaruhi Kinerja Keuangan Perusahaan. Media Ekonomi Dan Manajemen. https://doi.org/10.24856/mem.v32i1.465

Nirmalasari, L., \& Ulum, S. (2014). Corporate Social Responsibility : Respon Publik dan dampaknya Pada Corporate Image. Study \& Accounting Research.

Oh, W., \& Park, S. (2015). The relationship between corporate social responsibility and corporate financial performance in Korea. Emerging Markets Finance and Trade. https://doi.org/10.1080/1540496X.2015.1039903

Otoritas Jasa Keuangan. (2018). Statistik Perbankan Indonesia 2017. Ojk.

Otoritas Jasa Keuangan. (2019). Statistik Perbankan Indonesia - Agustus 2019. OJK.

Park, E. (2019). Corporate social responsibility as a determinant of corporate reputation in the airline industry. Journal of Retailing and Consumer Services. https://doi.org/10.1016/j.jretconser.2018.11.013

Park, S. H. (2017). Corporate social responsibility, visibility, reputation and financial performance: empirical analysis on the moderating and mediating variables from Korea. Social Responsibility Journal. https://doi.org/10.1108/SRJ-01-2017-0012

Rudito, B. (2014). The Improvement of Community Economy as Impact of Corporate Social Responsibility Program: A Case Study in Pengalengan, Bandung, West Java, Indonesia. Procedia - Social and Behavioral Sciences. https://doi.org/10.1016/j.sbspro.2014.11.104

Rutledge, R. W., Karim, K. E., Aleksanyan, M., \& Wu, C. (2014). An examination of the relationship between corporate social responsibility and financial performance: The case of Chinese state-owned enterprises. Advances in Environmental Accounting and Management. https://doi.org/10.1108/S1479-359820140000005001

Saeidi, S. P., Sofian, S., Saeidi, P., Saeidi, S. P., \& Saaeidi, S. A. (2015). How does corporate social responsibility contribute to firm financial performance? The mediating role of competitive advantage, reputation, and customer satisfaction. Journal of Business Research. https://doi.org/10.1016/j.jbusres.2014.06.024

Salehi, M., Lari DashtBayaz, M., \& Khorashadizadeh, S. (2018). Corporate social responsibility and future financial performance: Evidence from Tehran Stock Exchange. EuroMed Journal of Business. https://doi.org/10.1108/EMJB-11-2017-0044

Sekhon, A. K., \& Kathuria, L. M. (2019). Analyzing the impact of corporate social responsibility on corporate financial performance: evidence from top Indian firms. Corporate Governance (Bingley). https://doi.org/10.1108/CG-04-2019-0135

Setiawan, S., \& Sari, R. M. (2018). Rentabilitas Bank Umum Syariah Sesudah Spin-Off Berdasarkan Tipe Pemisahannya Di Indonesia. Amwaluna: Jurnal Ekonomi Dan Kenangan Syariah. https://doi.org/10.29313/amwaluna.v2i1.3291

Setyowati, D. H. (2019). Pengaruh Efisiensi Operasional Terhadap Return On Assets Pada Bank Umum Syariah Di Indonesia. Masharif Al-Syariah: Jumal Ekonomi Dan Perbankan Syariah.

Su, L., Huang, S. (Sam), van der Veen, R., \& Chen, X. (2014). Corporate Social Responsibility, Corporate Reputation, Customer Emotions and Behavioral Intentions: A Structural Equation Modeling Analysis. Journal of China Tourism Research. https://doi.org/10.1080/19388160.2014.958606 
Su, L., Pan, Y., \& Chen, X. (2017). Corporate social responsibility: Findings from the Chinese hospitality industry. Journal of Retailing and Consumer Services. https://doi.org/10.1016/j.jretconser.2016.10.013

Taghian, M., D’Souza, C., \& Polonsky, M. J. (2015). A stakeholder approach to corporate social responsibility, reputation and business performance. Social Responsibility Journal. https://doi.org/10.1108/SRJ-06-2012-0068

Thao, D. T. T., \& Le, M. T. (2019). The Effect of Corporate Social Responsibility Disclosure on Corporate Financial Performance. International Journal of Business, Economics and Management. https://doi.org/10.18488/journal.62.2019.65.264.288

Tomak, S. (2014). Corporate Reputation and Financial Performance of Firms in Turkey. Niğde Üniversitesi İktisadi ve İdari Bilimler Fakültesi Dergisi, 7(1), 289-303.

Vinzi, V. E., Trinchera, L., \& Amato, S. (2010). PLS Path Modeling: Foundations, Recent Developments and Open Issues. In Handbook of Partial Least Squares. https://doi.org/10.1007/978-3-540-32827-8

Weng, P. S., \& Chen, W. Y. (2017). Doing good or choosing well? Corporate reputation, CEO reputation, and corporate financial performance. North American Journal of Economics and Finance. https://doi.org/10.1016/j.najef.2016.10.008 